\title{
Oreste Ghisalba at the Heart of Biotechnology
}

\author{
Beda M. Stadler*
}

Abstract: A personal account of the author's relationship with Oreste Ghisalba over a period of almost 30 years is given.

Keywords: Biotechnology · CTI · SPP Biotech

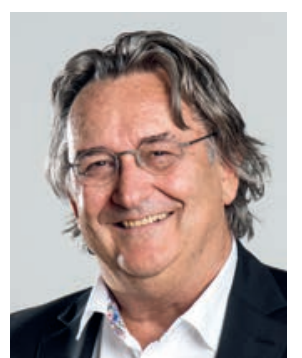

Beda M. Stadler, former director of the University Institute of Immunology at the Insel Hospital in Bern, is emeritus professor of Immunology from the Medical Faculty of the University of Bern. His major research interests were in basic research in the field of allergy and autoimmunity as well as applied research in the field of immunology. As former Vice President of the Commission for Technology and Innovation (CTI) Federal Department of Economic Affairs, Education and Research EAER Switzerland he headed the life science team and was a member of the CTI Start-up \& Entrepreneurship label board.

Professor Dr. Oreste Ghisalba died on December $4^{\text {th }}, 2018$. Thus, this is not an obituary but a personal reflection on the fact that many of us still miss him. Every encounter with him resulted in an avalanche of valuable information. All this is gone, but I minimally had the pleasure to accompany Oreste for almost 30 years and to know we are friends. It is understood that my view will be biased and despite the fact that writing about a dead friend is very sad, I have to smile while looking back. He deserves a broad look at his deeds and the hope not to be forgotten.

Often, when it was my turn to introduce Oreste, I called him the "dinosaur of biotechnology". For younger scientists this was not really funny as it seemed out of context. For me it was, as I met him during the "labor pains" of biotechnology in Switzerland. It was a meeting in Zurich organized by Oreste in his function as the Program Director of the Swiss Priority Program Biotechnology of the Swiss National Science Foundation (SPP Biotech). I participated because this was probably the first time that Swiss academia talked about biotech as a true business and not only beer brewing. Charles Weissman was the star speaker and was also admired as a cofounder of the first Swiss biotech company, Biogen, already founded in 1978 !

In other words, SPP Biotech found the perfect program director in 1992. Oreste was a chemist with profound knowledge in microbiology. At that time nobody was called a 'biotechnologist'; the field was about to start and the involved scientists were still chemists, molecular biologists or scientists in basic medicine. As we envied the United States for fostering this new field of opportunities with biotech centers all over the country, our SPP Biotech was the hope to stimulate the scientific community. Indeed, every- body started to benefit from the large network of Oreste, but new companies only appeared slowly. If I had called Oreste "dinosaur" he usually smiled with forgiveness, but he did not like the term "midwife", even though it described his role best in the early days of Swiss biotechnology.

These early days were overshadowed by political events, namely by the Genschutzinitiative, that started in 1992. It was also the beginning of an anti-scientific movement that still hampers green biotechnology. Most people have forgotten that during the debate of the initiative many of our citizens wanted a sales stop of recombinant insulin, the only biotech product on the market at the time. In 1998 luckily the Genschutzinitiative was rejected by a majority of Swiss and could not endanger the fruitful continuation of SPP Biotech. SPP Biotech was actually at risk and it was wise that Oreste kept the program and his temper out of politics.

The SNF, mainly supporting basic science, was not the funding agency for further support of biotechnology. Applied sciences turned to the Commission of Technology and Science, the smaller promotion agency of the government. This commission had a section for medicinal technology (Medtech) and an additional one-man show, Oreste Ghisalba, as the only biotechnology reviewing process. When I joined CTI, we met again to review the ever-increasing number of requests from early biotech endeavors. Many applicants were a spillover from SPP Biotech. Later Oreste became the head of CTI-Biotech and I was allowed to head CTILife Sciences. Our two-man show had grown and became almost the biggest section within CTI before it was transformed into Innosuisse in 2018.

During CTI times Oreste had a number of focuses. One focus made both of us hated by the universities of applied sciences initially. Namely at the time it was almost impossible for them to obtain research support from SNF. CTI was the only agency where they could apply. Oreste realized that our universities were too academic for rapidly developing applied biotechnology and the applied universities were not academic enough to become a serious birthplace for companies. Thus, by slightly hardening the CTI funding rules, the applied universities became more productive and are today a significant building block of Swiss biotechnology. In the final years of CTI applications of all types of Swiss universities had the same high levels.

In my eyes one of Orestes greatest achievements was based on a Benedictine proverb: "It's easier to ask forgiveness than to get permission." Namely, he interpreted the CTI ordinance in a way 
that made it possible to support the foundation of 'Swiss Biotech Association' in 1998. Of course, he also took an active role in the annually published 'Biotech Report' which was a useful mirror for the development of biotechnology in Switzerland. To his friends Oreste liked to give a book as present, but all colleagues received a biotech report every year.

Let me end with some personal remarks. It was often claimed that Oreste was narcoleptic. That is not true. Though it is true that he fell asleep in many meetings or hearings, but only to wake up before the end of a presentation to ask a crucial question demonstrating that he actually did not sleep. I miss him as well for brightening up every boring meeting by making some humorous comments. Oreste would even think of his friends during his travels abroad. From his last stay in Tibet he brought me, an atheist, a solar powered prayer mill.
Whether a dinosaur or a midwife for the development of Swiss biotechnology, one thing is not disputable: Oreste Ghisalba is at the heart of Swiss biotechnology.

Received: February 22, 2020

\section{License and Terms}

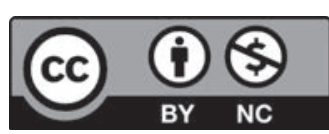

This is an Open Access article under the terms of the Creative Commons Attribution License CC BY_NC 4.0. The material may not be used for commercial purposes.

The license is subject to the CHIMIA terms and conditions: (http:// chimia.ch/component/sppagebuilder/?view=page \&id=12).

The definitive version of this article is the electronic one that can be found at doi:10.2533/chimia.2020.320 